\title{
EDITORIAL
}

\section{Notes from the Editors}

\author{
Henrik Åström Elmersjö \\ Anna Larsson
}

$\mathrm{T}$ his is the seventh issue of the Nordic Journal of Educational History and it contains three somewhat different articles from the Nordic field of educational history.

The first article presents an analysis of the impact of the school acts of 1814 in Denmark. Written by Christian Larsen, who was one of the authors of the second volume of the very ambitious, five volume series on Danish school-history (Dansk skolehistorie, vol. 1-5, 2013-2015), it makes an interesting point outof the fact that five different acts were passed in 1814. The article focuses on how these different acts influenced the local administrations, the establishment and construction of school buildings, and the teacher education needed to realise the intentions of the acts.

In the second article, agricultural historian Karl Bruno discusses the support of higher forestry education in Ethiopia, given by the Swedish University of Agricultural Sciences. The article focuses on how the Swedish forestry experts designed progammes and it introduces the concept of "silvi-culture," (a combination of silvicultural and sociocultural aspects) which signifies the tensions given by diverse academic and social cultures. These differences were particularly visible in regards to the Swedish experts' way of seeing the forest as a concrete, physical place, absent from large parts of Ethiopia where the educational programme was to be implemented.

In the third article, historians Björn Furuhagen and Janne Holmén compare the discussions on and implementation of a new teacher education in Finland and Sweden. The authors discuss the similarities and differences regarding the ideals behind the transition to a university based teacher education, the impact of different agents in the discussions, and the outcomes of this transition.

We hope you will enjoy this issue and we wish to remind you of the upcoming seventh Nordic Educational History Conference in Trondheim, Norway, 19-20 September 2018. The theme of the conference will be education and society in change, and it will, apart from a lot of interesting discussions and opportunities to meet other educational historians, result in a special issue of the Nordic Journal of Educational History. 